\title{
PENGARUH PERLAKUAN LIMBAH DAN JENIS MORDAN KAPUR, TAWAS, DAN TUNJUNG TERHADAP MUTU PEWARNAAN KAIN SUTERA DAN KATUN MENGGUNAKAN LIMBAH CAIR GAMBIR (Uncaria Gambir Roxb)
}

\author{
The Effect of Waste Treatment and Mordant Kind of Lime, Alum, and \\ Ferous Salt on Dyeing Quality of Silk and Cotton Fabrics Using \\ Wastewater of Gambir (Uncaria Gambir Roxb)
}

\author{
Sofyan*, Failisnur, dan Salmariza. Sy \\ Balai Riset dan Standardisasi Industri Padang \\ JI. Raya LIK No. 23 Ulu Gadut Padang 25164 \\ *e-mail: sofyan@kemenperin.go.id
}

Diterima: 6 Juli 2015, revisi akhir: 18 September 2015 dan disetujui untuk diterbitkan: 4 Desember 2015

\begin{abstract}
ABSTRAK
Gambir adalah getah yang diperoleh dari ekstraksi panas daun dan ranting tanaman gambir yang diikuti pengempaan, sedimentasi, dan pasta yang terbentuk dicetak lalu dikeringkan. Menurut Sumatera Barat dalam angka, total produksi gambir Sumatera Barat selama tahun 2012 mencapai 14.220 ton. Dari jumlah tersebut akan dihasilkan lebih kurang 5.688.000 liter limbah cair per tahun. Limbah gambir merupakan hasil samping dari proses produksi gambir yang belum dimanfaatkan. Kandungan tanin yang tinggi dalam limbah cair ini merupakan bahan pewarna yang dapat digunakan sebagai pewarna tekstil. Tujuan penelitian adalah memanfaatkan limbah cair proses produksi gambir untuk pewarna kain sutera dan kain katun dengan perlakuan limbah cair yang tidak distabilkan dan yang distabilkan dengan mordan kapur $\left(\mathrm{CaCO}_{3}\right)$, tawas $\mathrm{Al}_{2}\left(\mathrm{SO}_{4}\right)_{3}$, dan tunjung $\left(\mathrm{FeSO}_{4}\right)$. Hasil penelitian menunjukkan bahwa pencelupan dengan limbah cair menggunakan mordan yang berbeda menghasilkan warna yang berbeda pula. Kain sutera dan katun yang diwarnai dengan limbah, baik yang tidak distabilkan ataupun yang distabilkan menghasilkan warna coklat kemerahan untuk yang dimordan dengan kapur, kuning cerah untuk yang dimordan dengan tawas, dan hijau lumut yang dimordan dengan tunjung. Bila dibandingkan antara sutera dan katun, maka penyerapan warna pada sutera lebih baik. Hal ini dapat dilihat dari warna yang lebih tua untuk perlakuan yang sama. Hasil pengujian ketahanan luntur warna terhadap pencucian $40^{\circ} \mathrm{C}$, terhadap sinar terang hari, dan terhadap penekanan panas umumnya berkisar antara baik sampai dengan baik sekali (skala 4-5).
\end{abstract}

Kata Kunci: Pewarnaan, limbah cair, gambir, sutera, katun

\section{ABSTRACT}

Gambier is an extract obtained from heat extraction of leaves and twigs of gambier plant followed by compression, sedimentation, and the formed paste is moulded and then dried. According to West Sumatra in figures, total production of gambier in West Sumatera in 2012 reached 14,220 tons. From the amount would be produced approximately 5,688,000 liters of liquid waste per year. The gambier waste is a by product of gambier production process which is untapped. High tannin content in the liquid waste is a dye that can be used as a textiles dye. The purpose of the research was to utilize liquid waste from gambier production process to dye silk and cotton fabrics with liquid waste treatment which was not stabilized or stabilized with mordant lime $\left(\mathrm{CaCO}_{3}\right)$, alum $\mathrm{Al}_{2}\left(\mathrm{SO}_{4}\right)_{3}$ and tunjung $\left(\mathrm{FeSO}_{4}\right)$. The results of the research showed that dyeing with liquid waste by using different mordant would generate different colors. Silk and cotton fabrics were dyed with waste, whether stabilized or not stabilized and mordanted with lime, alum, and tunjung generated a reddish brown color, bright yellow, and moss green respectively. When compared between silk and cotton, color absorption on silk was better. It could be seen from the darker color for the same treatment. The analysis results of color fastness to washing $40^{\circ} \mathrm{C}$, the bright day light, and heat pressing generally ranged between good to excellent (scale 4-5).

Keywords: Dyeing, liquid waste, gambier, silk, cotton 


\section{PENDAHULUAN}

Gambir adalah ekstrak kering dari ranting dan daun tanaman Uncaria gambir (Hunter) Roxb. Gambir merupakan tumbuhan yang termasuk dalam famili Rubiaceae dan komoditas perkebunan rakyat (Rahmawati N. dkk. 2012). Ekstrak kering ini diperoleh melalui ekstraksi panas daun dan ranting tanaman gambir yang diikuti pengempaan, sedimentasi, dan pasta yang terbentuk dicetak lalu dikeringkan. Pada saat penirisan pasta, sebelum dicetak, akan dihasilkan air tirisan yang merupakan limbah cair. Limbah cair proses produksi gambir merupakan cairan berwarna coklat sampai coklat kehitaman yang masih mengandung tanin dan dapat dimanfaatkan.

Tanaman gambir merupakan komoditas spesifik lokasi dan unggulan daerah provinsi Sumatera Barat. Usaha tani gambir adalah salah satu mata pencaharian untuk meningkatkan pendapatan petani. Gambir juga sebagai komoditas ekspor yang memiliki sumbangan besar terhadap Produk
Domestik Regional Bruto (PDRB) daerah yang pada gilirannya akan meningkatkan devisa Negara. Delapan puluh persen kebutuhan gambir dunia dipasok oleh Provinsi Sumatera Barat dengan negara tujuan Bangladesh, India, Pakistan, Taiwan, Jepang, Korea Selatan, Perancis, dan Swiss (Dhalimi, A. 2006).

Beberapa daerah penghasil gambir di Indonesia selain Sumatera Barat antara lain Sumatera Utara, Riau, Sumatera Selatan, dan Aceh. Menurut Riau dalam angka (2013), produksi gambir di Propinsi Riau tercatat 4.230 ton pada tahun 2012. Daerah lain dengan jumlah yang tidak terlalu banyak adalah Sumatera Selatan dengan jumlah 189 ton pada tahun 2010 (Profil dan investasi Sumatera Selatan, 2011). Produksi gambir di Sumatera Barat dan Sumatera Utara dapat dilihat pada Tabel 1. Daerah penghasil gambir utama di Propinsi Sumatera Barat adalah Kabupaten Lima Puluh Kota dan Pesisir Selatan dengan jumlah produksi seperti pada Tabel 1.

Tabel 1. Produksi gambir di Sumatera Barat dan Sumatera Utara

\begin{tabular}{cccc}
\hline Tahun & $\begin{array}{c}\text { Sumatera Barat } \\
\text { (ton) }\end{array}$ & $\begin{array}{c}\text { Sumatera Utara } \\
\text { (ton) }\end{array}$ & $\begin{array}{c}\text { Kab. Pesisir Selatan } \\
\text { (ton) }\end{array}$ \\
\hline 2012 & 14.220 & 1.789 & 3.089 \\
\hline 2011 & 14.025 & 1.889 & 2.894 \\
\hline 2010 & 13.845 & 1.877 & - \\
\hline 2009 & 13.932 & 1.861 & 3.318 \\
\hline 2008 & 13.930 & - & 3.320 \\
\hline
\end{tabular}

Sumber: BPS Propinsi Sumatera Barat (2013)

BPS Propinsi Sumatera Utara (2013)

Menurut data pada Tabel 1, total produksi gambir Sumatera Barat selama tahun 2012 mencapai 14.220 ton. Dari jumlah tersebut akan dihasilkan lebih kurang 5.688.000 liter limbah cair per tahun. Limbah ini merupakan hasil samping dari proses produksi gambir yang belum dimanfaatkan. Jumlah limbah cair gambir yang demikian besar merupakan sumber daya yang potensial untuk digunakan sebagai pewarna alami. Kandungan tanin yang tinggi dalam limbah cair ini merupakan bahan pewarna yang dapat digunakan sebagai pewarna tekstil.
Penelitian pemanfaatan gambir sebagai bahan alam untuk pewarna tekstil telah dilakukan oleh beberapa peneliti, namun penelitian pemanfatan limbah cairnya masih sedikit yang dipublikasikan. Pemanfaatan limbah cair proses produksi gambir mempunyai nilai tambah karena menggunakan bahan yang terbuang dan tidak dimanfaatkan. Selain itu, penggunaan bahan alam sebagai bahan pewarna alami pada produk tekstil merupakan salah satu cara yang dapat dilakukan untuk menggantikan bahan pewarna sintetis. Bila ditinjau dari aspek lingkungan, maka 
penggunaan bahan pewarna alami pada industri tekstil merupakan salah satu upaya untuk menciptakan green industry. Jerman adalah negara pertama yang berinisiatif melarang pembuatan dan penggunaan zat warna azo yang merupakan zat warna sintetik karena bersifat karsinogen. Belanda, India, dan beberapa negara lain juga mengikuti larangan tersebut (Patel, 2011).

Tanaman gambir merupakan salah satu dari berbagai jenis tanaman yang digunakan sebagai penghasil warna coklat atau campuran pada soga. Manfaat gambir sebagai pewarna tekstil adalah berdasarkan pada fenomena petani gambir yang sulit menghilangkan noda yang terdapat pada pakaiannya ketika mengekstraksi daun gambir (Lukas, 2011).

Failisnur dan Yeni (2013), melakukan penelitian stabilisasi limbah cair hasil pengolahan gambir dan aplikasinya sebagai pewarna pada kain sutera. Penelitian dilakukan dengan mengkondisikan limbah yang belum dipekatkan dan yang sudah dipekatkan. Pencelupan dilakukan pada proses dingin dan menggunakan pengikat warna kapur, tawas, dan tunjung. Dari hasil penelitian dilaporkan bahwa penggunaan limbah cair gambir terhadap kain sutera dapat menghasilkan kain sutera dengan arah warna merah kecoklatan, kuning keemasan, dan hijau lumut sampai hijau kehitaman dengan ketahanan luntur warna terhadap pencucian $40^{\circ} \mathrm{C}$; keringat asam atau basa; gosokan dan panas penyetrikaan pada umumnya menghasilkan nilai baik sampai sangat baik (nilai 4-5), terhadap cahaya terang (nilai sinar) adalah cukup sampai baik (nilai 3-4).

Failisnur dan Sofyan (2014), melaporkan sifat tahan luntur dan intensitas warna kain sutera dengan pewarna alam gambir pada kondisi pencelupan dan jenis fiksator yang berbeda. Penelitian dilakukan menggunakan larutan gambir 5\% dengan memvariasikan kondisi pencelupan panas $\left(60-70^{\circ} \mathrm{C}\right)$ dan dingin (suhu kamar) serta jenis pembangkit warna $\mathrm{Al}_{2}\left(\mathrm{SO}_{4}\right)_{3}, \mathrm{CaCO}_{3}$, dan $\mathrm{FeSO}_{4}$. Hasil penelitian didapatkan arah warna yang cukup variatif pada kain sutera mulai dari kuning, kuning keemasan, merah kecoklatan, coklat, hijau lumut sampai hijau kehitaman. Kondisi optimum diperoleh pada pencelupan panas $\left(60-70^{\circ} \mathrm{C}\right)$, jenis fiksator $\mathrm{CaO}$ yang menghasilkan intensitas dan ketuaan warna lebih tinggi (nilai K/S) sebesar 19,174 dan ketahanan luntur warna terhadap pencucian $40^{\circ} \mathrm{C}$, sinar terang hari dan penekanan panas bernilai baik sampai sangat baik (4-5).

Pada proses pewarnaan kain dengan limbah cair gambir, selalu digunakan mordan sebagai bahan pembangkit warna. Pada penelitian-penelitian sebelumnya, proses mordan dilakukan setelah bahan tekstil diwarnai dengan larutan pewarna kemudian dilanjutkan dengan proses mordan. Pemakaian mordan yang langsung ditambah pada larutan pewarnanya atau distabilkan belum pernah diuji coba. Penstabilan ini dimaksudkan agar zat warna dapat disimpan dalam waktu yang lama karena sifatnya yang mudah berjamur.

Tujuan penelitian adalah memanfaatkan limbah cair proses produksi gambir untuk pewarna kain sutera dan kain katun dengan perlakuan limbah cair yang tidak distabilkan dan yang distabilkan menggunakan pengikat warna (fiksasi) kapur $\left(\mathrm{CaCO}_{3}\right)$, tawas $\left(\mathrm{Al}_{2}\left(\mathrm{SO}_{4}\right)_{3}\right.$, dan tunjung $\left(\mathrm{FeSO}_{4}\right)$, serta melihat ketahanan luntur warna kain yang telah diwarnai.

\section{METODOLOGI PENELITIAN}

Bahan yang digunakan adalah limbah cair proses produksi gambir yang diambil dari industri pengempaan gambir yang ada di Nagari Siguntur, Kecamatan Koto XI Tarusan, Kabupaten Pesisir Selatan, Propinsi Sumatera Barat. Bahan-bahan untuk penelitian yaitu limbah cair proses produksi gambir, kain katun, kain sutera, bahan-bahan kimia untuk proses mordan yaitu kapur $\mathrm{CaCO}_{3}$, tawas $\mathrm{Al}_{2}\left(\mathrm{SO}_{4}\right)_{3}$, dan tunjung $\mathrm{FeSO}_{4}$, dan bahan-bahan kimia untuk analisis. Peralatan-peralatan yang digunakan antara lain peralatan untuk pencelupan seperti ember, timbangan, kompor, panci, peralatan gelas untuk analisis dan peralatan untuk pengujian.

Penelitian dilakukan dengan variasi perlakuan limbah cair (D), jenis kain (E), dan jenis mordan $(F)$. Perlakuan limbah cair dilakukan dengan dua cara yaitu limbah cair yang tidak distabilkan (D1) dan limbah cair yang distabilkan (D2). Pengikat warna yang digunakan ada tiga jenis yaitu kapur (F1), tawas (F2), dan tunjung (F3). Variasi kedua perlakuan tersebut digunakan untuk 
mewarnai kain sutera (E1) dan kain katun (E2). Dari variasi perlakuan-perlakuan tersebut terdapat 12 percobaan penelitian.

Sebelum dilakukan proses pencelupan, kain dimordan awal terlebih dahulu. Proses mordan awal kain katun dilakukan dengan menggunakan larutan tawas $5 \mathrm{~g} / \mathrm{L}$ dan soda abu $2 \mathrm{~g} / \mathrm{L}$. Untuk kain sutera, proses mordan dilakukan hanya menggunakan larutan tawas $5 \mathrm{~g} / \mathrm{L}$. Tawas dan soda abu yang sudah ditimbang kemudian dilarutkan dalam air dengan jumlah sesuai kebutuhan dimana kain yang digunakan terendam seluruhnya. Kain katun yang akan diwarnai dimasukkan ke dalam larutan tawas dan soda abu, sedangkan kain sutera dimasukkan ke dalam larutan tawas saja dan dipanaskan pada suhu $60-80^{\circ} \mathrm{C}$ selama lebih kurang satu jam. Setelah satu jam, api dimatikan dan kain dibiarkan dalam larutan selama lebih kurang satu malam. Kain yang telah direndam satu malam, dicuci sampai bersih dan dikeringkan. Kain yang telah kering, siap untuk dilakukan proses pencelupan.

Limbah cair gambir yang akan digunakan disaring menggunakan kain saring terlebih dahulu untuk menghilangkan kotoran-kotoran yang ada lalu dipanaskan sampai mendidih selama satu jam. Limbah cair yang distabilkan adalah limbah cair yang ditambahkan dengan larutan mordan untuk mencegah tumbuhnya jamur. Untuk limbah cair yang distabilkan, ditambahkan masingmasing dengan larutan tawas $0,7 \%$, larutan kapur $0,5 \%$, dan larutan tunjung $0,3 \%$, sedangkan untuk limbah cair yang tidak distabilkan tidak ditambahkan apapun.

Konsentrasi larutan mordan yang digunakan didasarkan pada studi yang dilakukan oleh Failisnur dan Yeni (2013) yaitu larutan tawas $0,7 \%$, larutan kapur $0,5 \%$, dan larutan tunjung $0,3 \%$. Jumlah larutan mordan yang digunakan disesuaikan dengan jumlah kain yang akan dicelup. Larutan didiamkan selama satu malam dan hanya diambil bagian filtratnya saja, sedangkan endapannya tidak digunakan.

Prosedur pencelupan dilakukan dengan proses panas dengan cara mencelupkan kain kering angin yang sudah dimordan ke dalam limbah cair gambir yang sudah dipanaskan pada suhu $70-80^{\circ} \mathrm{C}$ selama 10 menit. Kain yang sudah dicelup, dikeringkan sampai kering angin. Setelah kering angin, pencelupan diulangi sampai tiga kali. Setelah tiga kali, kain siap untuk dimordan.

Kain yang sudah melalui proses pencelupan dengan limbah cair gambir, selanjutnya dimordan dengan larutan mordan. Kain hasil proses mordan kemudian dikeringkan, setelah kering, dicuci kemudian dikeringkan.

Kain kering yang sudah dicelup dan dimordan selanjutnya diuji terhadap ketahanan luntur warna terhadap pencucian $40^{\circ} \mathrm{C}$ sesuai SNI ISO 105 - C $06: 2010$ meliputi: perubahan warna sesuai SNI ISO 105-A $02: 2010$, penodaan warna terhadap asetat, kapas, poliamida, poliester, akrilat, dan wool sesuai SNI ISO 105 - A 03 : 2010. Ketahanan luntur warna terhadap sinar terang hari sesuai SNI ISO 105-B $01: 2010$. Ketahanan luntur warna terhadap penekanan panas sesuai SNI ISO $105-X I I$ : 2010 meliputi: nilai perubahan warna, nilai perubahan warna kapas kering dan kapas basah.

Penilaian spesifikasi kolorimetrik menggunakan skala abu-abu (Grey scale) untuk perubahan warna dan skala penodaan (staining scale) untuk penodaan warna pada kain putih seperti pada Tabel 2. Spesifikasi yang tepat dari warna abu-abu standar dan perbedaan warna Gray Scale maupun Staining Scale dihitung dengan rumus nilai kekromatikan Adams dalam satuan C.D (Color Difference) seperti pada rumus 1.

Kriteria penilaiannya adalah: nilai 5 (baik sekali, tidak ada perubahan warna kain atau penodaan warna terhadap bahan lain), nilai 4 (baik, sedikit terjadi perubahan atau penodaan warna), nilai 3 (cukup, terjadi perubahan atau penodaan warna), nilai 2 (sedang, terjadi perubahan atau penodaan warna yang menyolok) dan nilai 1 (kurang, terjadi perubahan dan penodaan warna yang sangat menyolok). Selain uji ketahanan luntur warna, dianalisis juga intensitas warna kain yang dihasilkan terhadap masing-masing perlakuan dengan metode spektrofotometer sinar tampak. 
Tabel 2. Nilai Tahan Luntur Warna dan Color Difference (CD) pada Grey Scale (GS) dan Staining Scale (SS)

\begin{tabular}{cccc}
\hline \multirow{2}{*}{$\begin{array}{c}\text { Nilai } \\
\text { Tahan } \\
\text { Luntur }\end{array}$} & \multicolumn{2}{c}{ Perbedaan Warna (CD) } & \\
\cline { 2 - 3 } Warna & $\begin{array}{c}\text { Perubahan Warna } \\
\text { GS }\end{array}$ & $\begin{array}{c}\text { Penodaan Warna } \\
\text { SS }\end{array}$ & Penilaian \\
\hline 5 & 0 & 0,0 & Baik sekali \\
$4-5$ & 0,8 & 2,0 & Baik \\
4 & 1,5 & 4,0 & Baik \\
$3-4$ & 2,1 & 5,6 & Cukup baik \\
3 & 3,0 & 8,0 & Cukup \\
$2-3$ & 4,2 & 11,3 & Kurang \\
2 & 6,0 & 16,0 & Kurang \\
$1-2$ & 8,5 & 22,6 & Jelek \\
1 & 12,0 & 32,0 & Jelek \\
\hline
\end{tabular}

Sumber: Badan Standardisasi Nasional, 1989.

$40\left[(0,23 \wedge V y)^{2}+\{\Lambda(V x-V y)\}^{2}+\{0,4 \wedge(V z-V y)\}^{2}\right]^{0,5}$

dimana:

Vx, Vy dan Vz adalah modifikasi dari hargaharga tristimulus $X, Y$ dan $Z$

\section{HASIL DAN PEMBAHASAN}

\section{Pengamatan Arah Warna Kain Sutera dan Kain Katun}

Pewarnaan kain sutera dan katun dengan perlakuan jenis mordan (pengikat warna) yang berbeda yaitu $\mathrm{CaCO}_{3}, \mathrm{Al}_{2}\left(\mathrm{SO}_{4}\right)_{3}$, dan $\mathrm{FeSO}_{4}$ akan menghasilkan kain dengan arah warna yang berbeda-beda seperti ditampilkan pada Gambar 1. Jenis mordan kapur yang merupakan garam $\mathrm{CaCO}_{3}$ menghasilkan arah warna coklat kemerahan. $\mathrm{Al}_{2}\left(\mathrm{SO}_{4}\right)_{3}$ menghasilkan warna ke arah coklat kekuningan, sedangkan menggunakan mordan $\mathrm{FeSO}_{4}$ menghasilkan arah warna hijau. Perlakuan limbah yang tidak distabilkan dan yang distabilkan tidak memberikan pengaruh yang berbeda terhadap arah warna. Proses mordan dapat membuat variasi warna yang lebih beragam. Mordan yang mengandung garam-garam logam yang berbeda akan menghasilkan warna yang berbeda.

Beberapa permasalahan pada penggunaan pewarna alam untuk tekstil adalah terbatasnya nuansa warna yang dihasilkan, hasil reproduksi, masalah pencampuran, dan sifat tahan luntur warna yang tidak memadai (Sachan dan Kapoor,
2007; Siva, 2007). Masalah tersebut dapat diatasi dengan menggunakan garam logam atau mordan yang menghasilkan afinitas antara kain dan pewarna (Vankar et al, 2009;. Samanta dan Agarwal, 2009).

Proses mordan adalah perlakuan serat tekstil dengan garam-garam logam atau zat bahan pembentuk kompleks lainnya yang mengikat bahan pewarna alam ke dalam serat tekstil. Proses mordan dapat dilakukan dengan pre-mordan, simultan mordan, atau post-mordan (Samanta and Agarwal, 2009). Perbedaan jenis dan kombinasi mordan dapat diaplikasikan pada serat tekstil untuk mendapatkan variasi atau nuansa warna yang berbeda (Samanta and Agarwal, 2009).

Seperti halnya kain sutera, pewarnaan kain katun dengan perlakuan jenis mordan yang berbeda yaitu kapur $\mathrm{CaCO}_{3}$, tawas $\mathrm{Al}_{2}\left(\mathrm{SO}_{4}\right)_{3}$ dan tunjung $\mathrm{FeSO}_{4}$ juga menghasilkan kain dengan warna yang berbeda-beda seperti ditampilkan pada Gambar 1. Arah warna yang dihasilkan hampir sama, tetapi dengan warna yang lebih muda dibandingkan dengan kain sutera. Mordan kapur akan menghasilkan arah warna coklat tua. Fiksasi menggunakan mordan tawas menghasilkan warna ke arah coklat muda, sedangkan menggunakan tunjung menghasilkan arah warna hijau. Perlakuan limbah yang tidak distabilkan dan yang distabilkan tidak memberikan pengaruh yang berbeda terhadap arah warna. 
Hasil pewarnaan kain sutera pada berbagai interaksi perlakuan

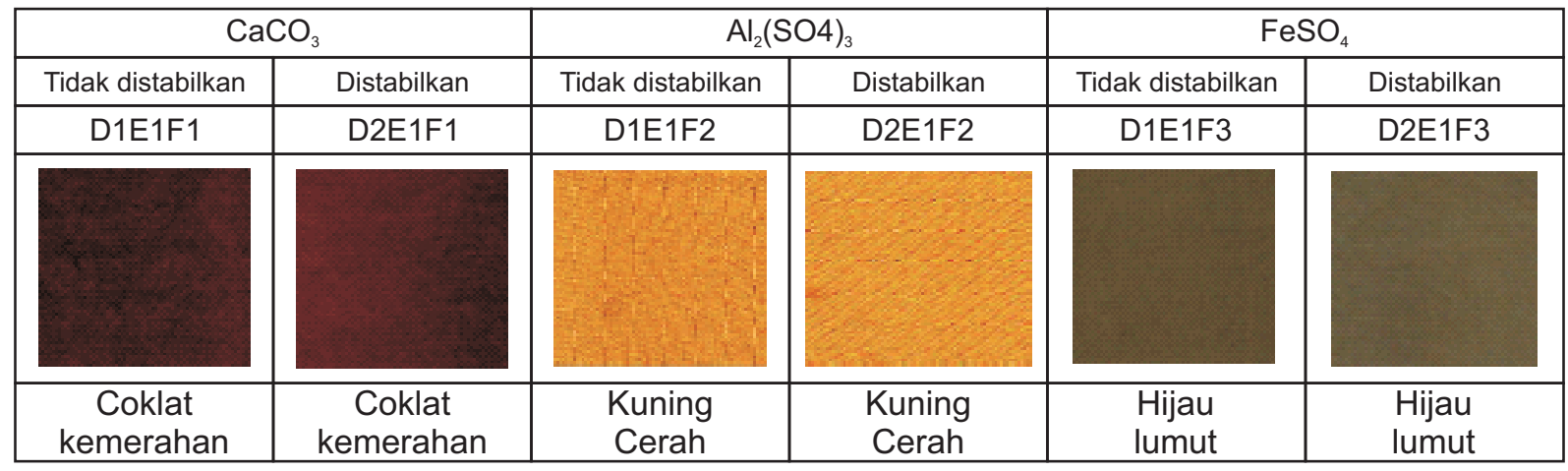

Hasil pewarnaan kain katun pada berbagai interaksi perlakuan

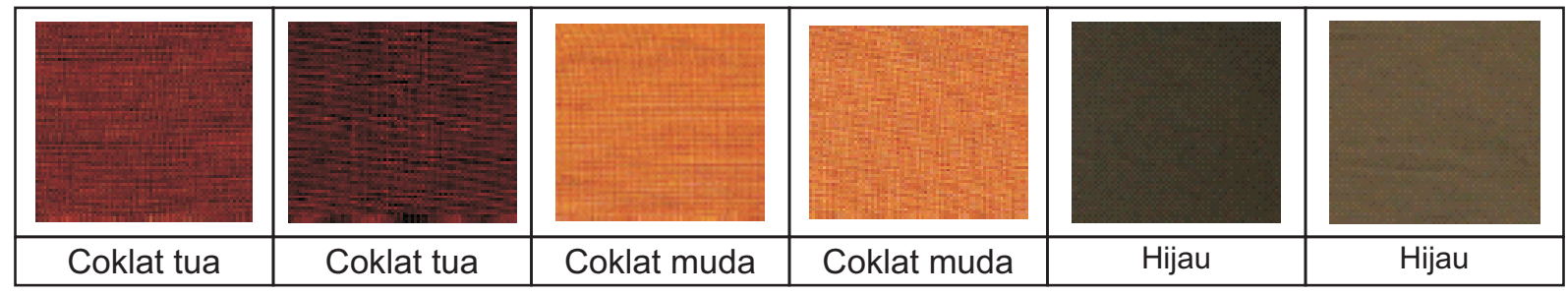

Gambar 1. Hasil pewarnaan kain sutera dan katun pada berbagai interaksi perlakuan

Hasil pengikat warna dengan tunjung sesuai dengan hasil riset yang dilakukan oleh Etherington (2002) bahwa tanin terkondensasi dalam larutan garam $\mathrm{Fe}^{3+}$ akan menghasilkan warna hijau kehitaman. Pengikat warna tunjung merupakan garam yang mengandung logam $\mathrm{Fe}^{3+}$. Hal ini terlihat juga pada kain yang dimordan dengan tunjung yang merupakan garam $\mathrm{FeSO}_{4}$ menghasilkan nuansa warna coklat ke arah hijau. Menurut Suheryanto (2010), fungsi dari larutan fixer (mordan) pada pewarnaan tekstil yang menggunakan pewarna alam adalah untuk meningkatkan ketuaan atau intensitas warna dan memperkuat ikatan antar serat dan zat warna, sehingga dapat mencegah degradasi pigmen warna.

Zarkogianni et al, (2010) melaporkan bahwa proses mordan dapat memperbaiki penyerapan warna dan sifat ketahanan luntur warna pada kain katun. Beberapa mordan yang sering digunakan pada pewarnaan tekstil dengan warna alam adalah aluminium potassium sulphate, potassium dichromate, copper sulphate, zinc chloride, iron(III) chloride, iron(II) sulphate and tin chloride.

\section{Pengujian Ketahanan Luntur Warna Kain Sutera dan Katun terhadap Pencucian $40^{\circ} \mathrm{C}$}

Hasil pengujian ketahanan luntur warna kain sutera dan katun dari variasi perlakuan limbah dan jenis mordan dapat dilihat pada Tabel 3. Pengujian ketahanan luntur warna terhadap pencucian $40^{\circ} \mathrm{C}$ dilakukan terhadap perubahan warna dan penodaan warna. Diantara jenis mordan yang digunakan, sutera yang dimordan dengan kapur menghasilkan nilai perubahan warna dan penodaan warna paling baik dibandingkan dengan tawas dan tunjung. Hal ini dapat dilihat dari rata-rata nilai pengujian antara baik sampai baik sekali (4 dan 5).

Tahan luntur warna adalah resistansi bahan untuk mengubah karakteristik warna atau tingkat transfer pewarna terhadap bahan putih yang bersentuhan dengannya (Samanta and Agarwal, 2009). Sifat ketahanan luntur warna terhadap sinar, pencucian, dan gosokan merupakan sifat yang sangat penting pada serat tekstil (Kulkarni et al., 2011).

Bila dibandingkan antara limbah yang tidak distabilkan dan limbah yang distabilkan, maka ada sedikit perbedaan terhadap pengujian ketahanan luntur warna 
terhadap pencucian $40^{\circ} \mathrm{C}$. Hal ini dapat dilihat dari nilai pengujian yang hampir sama untuk kedua perlakuan tersebut seperti data pada Tabel 3. Perbedaan terlihat pada kain katun dengan tawas untuk parameter perubahan warna. Limbah yang tidak distabilkan memiliki nilai 3, sedangkan yang distabilkan memiliki nilai lebih rendah yaitu 2-3.

Demikian juga halnya pada nilai penodaan warna (kapas dan poliamida) pada sutera yang menggunakan mordan kapur dengan limbah yang distabilkan mempunyai nilai cukup (3) lebih rendah dibandingkan pencelupan menggunakan limbah yang tidak distabilkan dengan nilai 45.

Dari seluruh perlakuan, baik jenis mordan atau perlakuan limbah, penggunaan mordan $\mathrm{CaCO}_{3}$ dan pencelupan menggunakan limbah yang tidak distabilkan merupakan perlakuan yang terbaik untuk kain sutera dengan nilai rata-rata antara baik sampai baik sekali (4 dan 5). Hasil ini sejalan dengan studi yang dilakukan oleh Chairat et al. (2007) yang mengekstrak komponen zat warna dari buah manggis (Garcinia mangostana Linn) yang digunakan untuk mewarnai benang katun dan sutera. Hasil studi menunjukkan bahwa pewarnaan katun menggunakan metode post mordan dengan Ferous Sulfat dan Calsium Hidroksida tidak hanya memberikan nuansa warna yang lebih tajam tetapi juga menghasilkan ketahanan luntur warna terhadap pencucian dan sinar yang lebih baik dibandingkan dengan mordan alum, zinc tetrafluoroborate, atau tanpa mordan.

Tabel 3. Hasil pengujian ketahanan luntur warna kain sutera dan katun terhadap pencucian $40^{\circ} \mathrm{C}$

\begin{tabular}{|c|c|c|c|c|c|c|c|}
\hline \multirow{4}{*}{$\begin{array}{l}\text { Jenis } \\
\text { Kain }\end{array}$} & \multirow{4}{*}{ Jenis Uji } & \multicolumn{6}{|c|}{ Hasil uji (variasi jenis mordan dan perlakuan limbah) } \\
\hline & & \multicolumn{2}{|c|}{ Kapur } & \multicolumn{2}{|c|}{ Tawas } & \multicolumn{2}{|c|}{ Tunjung } \\
\hline & & $\begin{array}{c}\text { Tidak } \\
\text { distabilkan }\end{array}$ & Distabilkan & $\begin{array}{c}\text { Tidak } \\
\text { distabilkan }\end{array}$ & Distabilkan & $\begin{array}{c}\text { Tidak } \\
\text { distabilkan }\end{array}$ & Distabilkan \\
\hline & & D1E1F1 & D2E1F1 & D1E1F2 & D2E1F2 & D1E1F3 & D2E1F3 \\
\hline \multirow{8}{*}{ Sutera } & $\begin{array}{l}\text { - Perubahan } \\
\text { warna }\end{array}$ & 4 & 4 & $3-4$ & $3-4$ & 3 & 3 \\
\hline & $\begin{array}{l}\text { - Penodaan } \\
\text { warna }\end{array}$ & & & & & & \\
\hline & Asetat & $4-5$ & $4-5$ & 4 & 4 & 4 & 4 \\
\hline & Kapas & 4 & 3 & 3 & 3 & $3-4$ & $3-4$ \\
\hline & Poliamida & $4-5$ & 3 & $3-4$ & $3-4$ & $3-4$ & $3-4$ \\
\hline & Poliester & $4-5$ & $4-5$ & $4-5$ & $4-5$ & $4-5$ & $4-5$ \\
\hline & Akrilat & $4-5$ & $4-5$ & $4-5$ & $4-5$ & $4-5$ & $4-5$ \\
\hline & Wool & $4-5$ & $4-5$ & 4 & 4 & $4-5$ & $4-5$ \\
\hline \multirow{8}{*}{ Katun } & $\begin{array}{l}\text { - Perubahan } \\
\text { warna }\end{array}$ & 4 & 4 & 3 & $2-3$ & 3 & 3 \\
\hline & $\begin{array}{l}\text { - Penodaan } \\
\text { warna }\end{array}$ & & & & & & \\
\hline & Asetat & $4-5$ & $4-5$ & $4-5$ & $4-5$ & $4-5$ & $4-5$ \\
\hline & Kapas & 4 & 4 & 4 & 4 & $4-5$ & $4-5$ \\
\hline & Poliamida & $4-5$ & 3 & 4 & $4-5$ & $4-5$ & $4-5$ \\
\hline & Poliester & $4-5$ & $4-5$ & $4-5$ & $4-5$ & $4-5$ & $4-5$ \\
\hline & Akrilat & $4-5$ & $4-5$ & $4-5$ & $4-5$ & $4-5$ & $4-5$ \\
\hline & Wool & $4-5$ & $4-5$ & $4-5$ & $4-5$ & $4-5$ & $4-5$ \\
\hline
\end{tabular}

Pengujian ketahanan luntur warna kain katun terhadap pencucian $40^{\circ} \mathrm{C}$ dilakukan terhadap perubahan warna dan penodaan warna. Diantara jenis pengikat warna yang digunakan, katun yang difiksasi dengan kapur menghasilkan nilai perubahan warna paling baik dibandingkan dengan tawas dan tunjung. Hal ini dapat dilihat dari pengujian yang bernilai baik (nilai 4) yang berarti hanya sedikit terjadi perubahan warna pada pencucian $40^{\circ} \mathrm{C}$. Bila dibandingkan antara limbah yang tidak distabilkan dan limbah yang distabilkan, maka tidak ada perbedaan yang nyata terhadap perubahan warna pada pengujian ketahanan luntur warna terhadap pencucian $40^{\circ} \mathrm{C}$ kecuali pada limbah yang 
distabilkan dan difiksasi dengan tawas dimana terjadi perubahan warna yang menyolok (nilai 2-3).

Hasil pengujian penodaan warna menunjukkan hasil yang tidak berbeda nyata untuk semua perlakuan yaitu rata-rata bernilai 4-5, kecuali pada limbah yang distabilkan dan difiksasi dengan kapur yang bernilai cukup (3) pada penodaan warna poliamida. Ditinjau dari pengujian ketahanan luntur warna terhadap pencucian $40^{\circ} \mathrm{C}$, baik untuk perubahan warna dan penodaan warna, maka kain katun yang dicelup dengan limbah yang tidak distabilkan dan dimordan dengan kapur merupakan perlakuan terbaik.

Ketahanan luntur warna yang baik terhadap pencucian disebabkan oleh proses mordan yang dapat memperbaiki sifat ketahanan luntur warna. Hou et al. (2008) melakukan studi pewarnaan dan sifat-sifat beberapa metode mordan terhadap kain wol menggunakan pewarna katechin yang dimurnikan dengan membran mikro filtrasi. Hasilnya menunjukkan kain wol yang diwarnai memiliki ketahanan luntur warna yang baik terhadap pencucian, keringat basa, dan gosokan kering.

\section{Pengujian Ketahanan Luntur Warna Kain Sutera dan Katun terhadap Sinar}

Pengujian ketahanan luntur warna kain sutera dan katun terhadap sinar terang hari ditampilkan pada Tabel 4. Perlakuan limbah, baik yang tidak distabilkan maupun yang distabilkan pada sutera tidak memberikan pengaruh yang berbeda nyata pada pengujian ketahanan luntur warna terhadap sinar. Hasil uji ketahanan luntur warna untuk perlakuan limbah dan jenis mordan adalah sama untuk semua interaksi perlakuan. Ketahanan luntur terhadap sinar kain katun pada pemakaian jenis mordan kapur dan tunjung terlihat sedikit perbedaan, namun pada pemakaian mordan tawas tidak terlihat ada perbedaan. Ketahanan luntur warna terhadap sinar untuk limbah yang tidak distabilkan memiliki nilai 4 untuk mordan kapur dan 3-4 untuk tunjung. Nilai ini lebih rendah dibandingkan dengan perlakuan pada limbah yang distabilkan yaitu 4-5.
Bila dilihat dari jenis mordan atau pengikat warna, maka perlakuan dengan mordan kapur memberikan hasil pengujian ketahanan luntur warna terhadap sinar paling baik dan lebih baik dibandingkan dengan tawas dan tunjung dengan hasil baik (4), sedangkan untuk tawas dan tunjung dengan nilai cukup (3).

Beberapa hasil ketahanan luntur warna terhadap sinar pada studi ini hampir sama dengan studi yang dilakukan oleh Mongkholrattanasit et al., (2011). Studi dilakukan menggunakan pewarna alam dari ekstrak daun eucalyptus pada kain sutera dan wool menggunakan mordan ferrous dan diperoleh hasil ketahanan luntur warna terhadap pencucian dan keringat adalah baik sampai baik sekali (4-5), sedangkan ketahanan luntur warna terhadap sinar adalah cukup sampai baik (3-4).

Dari tiga jenis mordan yang digunakan pada kain katun, penggunaan kapur menghasilkan ketahanan luntur warna terhadap sinar paling baik dengan nilai 4 untuk limbah yang tidak distabilkan dan 4-5 untuk limbah yang distabilkan. Perlakuan lain yang mempunyai nilai baik (4-5) adalah pengikat warna tunjung untuk limbah yang distabilkan. Ketahanan luntur warna terhadap sinar pada proses mordan dengan tawas menghasilkan nilai cukup (3), paling rendah dibandingkan perlakuan lainnya. Bila ditinjau dari perlakuan limbah, maka perlakuan limbah yang tidak distabilkan dan yang distabilkan untuk pengikat warna yang sama menghasilkan ketahanan luntur warna terhadap sinar yang tidak begitu berbeda seperti ditampilkan pada Tabel 4.

Beberapa pewarna alam memberikan sifat ketahanan luntur warna yang kurang baik terhadap sinar. Proses mordan merupakan salah satu proses yang dapat memperbaiki sifat ketahanan luntur warna terhadap sinar. Kulkarni et al., (2011) melakukan studi pewarna alam kain katun dengan kulit pomegranat dan melaporkan ketahanan luntur warna yang baik diperoleh pada kain katun yang diwarnai dengan ekstrak pewarna dari kulit pomegranate karena terbentuknya komplek dengan logam mordan yang melindungi chromatophore dari degradasi fotolitik. 
Tabel 4. Hasil pengujian ketahanan luntur warna kain sutera dan katun terhadap sinar

\begin{tabular}{ccccccc}
\hline & \multicolumn{4}{c}{ Hasil uji (variasi jenis mordan dan perlakuan limbah) } \\
\cline { 2 - 7 } $\begin{array}{l}\text { Jenis } \\
\text { Kain }\end{array}$ & \multicolumn{2}{c}{ Kapur } & \multicolumn{3}{c}{ Tawas } & \multicolumn{2}{c}{ Tunjung } \\
& $\begin{array}{c}\text { Tidak } \\
\text { distabilkan }\end{array}$ & Distabilkan & $\begin{array}{c}\text { Tidak } \\
\text { distabilkan }\end{array}$ & Distabilkan & $\begin{array}{c}\text { Tidak } \\
\text { distabilkan }\end{array}$ & Distabilkan \\
\cline { 2 - 7 } & D1E1F1 & D2E1F1 & D1E1F2 & D2E1F2 & D1E1F3 & D2E1F3 \\
\hline Sutera & 4 & 4 & 3 & 3 & 3 & 3 \\
\hline Katun & 4 & $4-5$ & 3 & 3 & $3-4$ & $4-5$ \\
\hline
\end{tabular}

\section{Pengujian Ketahanan Luntur Warna Kain Sutera dan Katun terhadap Penekanan Panas}

Pengujian ketahanan luntur warna kain sutera dan katun terhadap penekanan panas dilakukan dengan melihat nilai perubahan warna dan nilai penodaan warna seperti pada Tabel 5. Dari hasil pengujian untuk kain sutera dapat dilihat bahwa perlakuan limbah dan jenis mordan tidak memberikan pengaruh pada pengujian ketahanan luntur warna terhadap penekanan panas. Semua perlakuan bernilai baik (skala 4-5) yang berarti hanya sedikit terjadi perubahan dan penodaan warna.

Hasil ini lebih baik bila dibandingkan dengan riset sejenis yang menggunakan pewarna alam lain. Kwartiningsih et al., (2009) melakukan studi mengenai zat pewarna alami tekstil dari kulit buah manggis dan dari hasil pengujian ketahanan luntur warna terhadap gosokan kering diperoleh nilai 3-4 (cukup baik) dan gosokan basah diperoleh nilai 3 (cukup).

Untuk kain katun, dari hasil pengujian dapat dilihat bahwa perlakuan limbah dan mordan tidak begitu memberikan pengaruh pada pengujian ketahanan luntur warna terhadap penekanan panas. Semua perlakuan bernilai baik (skala 4-5) yang berarti hanya sedikit terjadi perubahan dan penodaan warna, kecuali pada perlakuan kapur untuk limbah yang distabilkan mempunyai nilai cukup baik (3-4) yang berarti cukup terjadi perubahan dan penodaan warna.

Beberapa hasil yang diperoleh hampir sama dengan studi yang dilakukan oleh Mongkholrattanasit et al., (2011) yang melaporkan ketahanan luntur warna terhadap gosokan kain katun sutera dan katun menggunakan pewarna daun eucalyptus bernilai cukup sampai baik (3-4).

Tabel 5. Hasil pengujian ketahanan luntur warna kain sutera dan katun terhadap penekanan panas

\begin{tabular}{|c|c|c|c|c|c|c|c|}
\hline \multirow{4}{*}{$\begin{array}{l}\text { Jenis } \\
\text { Kain }\end{array}$} & \multirow{4}{*}{ Jenis Uji } & \multicolumn{6}{|c|}{ Hasil uji (variasi jenis mordan dan perlakuan limbah) } \\
\hline & & \multicolumn{2}{|c|}{ Kapur } & \multicolumn{2}{|c|}{ Tawas } & \multicolumn{2}{|c|}{ Tunjung } \\
\hline & & $\begin{array}{c}\text { Tidak } \\
\text { distabilkan }\end{array}$ & Distabilkan & $\begin{array}{c}\text { Tidak } \\
\text { distabilkan }\end{array}$ & Distabilkan & $\begin{array}{c}\text { Tidak } \\
\text { distabilkan }\end{array}$ & Distabilkan \\
\hline & & D1E1F1 & D2E1F1 & D1E1F2 & D2E1F2 & D1E1F3 & D2E1F3 \\
\hline \multirow{4}{*}{ Sutera } & $\begin{array}{l}\text { Nilai perubahan } \\
\text { warna }\end{array}$ & $4-5$ & $4-5$ & $4-5$ & $4-5$ & $4-5$ & $4-5$ \\
\hline & $\begin{array}{l}\text { Nilai penodaan } \\
\text { warna }\end{array}$ & & & & & & \\
\hline & - Kapas kering & $4-5$ & $4-5$ & $4-5$ & $4-5$ & $4-5$ & $4-5$ \\
\hline & - Kapas basah & $4-5$ & $4-5$ & $4-5$ & $4-5$ & $4-5$ & $4-5$ \\
\hline \multirow{4}{*}{ Katun } & $\begin{array}{l}\text { Nilai perubahan } \\
\text { warna }\end{array}$ & $4-5$ & $3-4$ & $4-5$ & $4-5$ & $4-5$ & $4-5$ \\
\hline & $\begin{array}{l}\text { Nilai penodaan } \\
\text { warna }\end{array}$ & & & & & & \\
\hline & - Kapas kering & $4-5$ & $4-5$ & $4-5$ & $4-5$ & $4-5$ & $4-5$ \\
\hline & - Kapas basah & $4-5$ & $4-5$ & $4-5$ & $4-5$ & $4-5$ & $4-5$ \\
\hline
\end{tabular}




\section{KESIMPULAN}

Limbah cair gambir, baik yang distabilkan ataupun yang tidak, menghasilkan arah warna yang berbeda dengan mordan yang berbeda. Arah warna yang dihasilkan adalah merah kecoklatan untuk yang dimordan dengan kapur $\mathrm{CaCO}_{3}$, kuning cerah untuk yang dimordan dengan tawas $\mathrm{Al}_{2}\left(\mathrm{SO}_{4}\right)_{3}$, dan hijau tua (hijau lumut) untuk yang dimordan dengan tunjung $\mathrm{FeSO}_{4}$. Penyerapan warna pada kain sutera lebih baik dibandingkan dengan kain katun, dimana dengan menggunakan mordan yang sama, warna yang dihasilkan pada kain sutera lebih tua dari pada kain katun.

Pada pengujian ketahanan luntur warna terhadap pencucian, dari seluruh perlakuan, baik jenis mordan atau perlakuan limbah, penggunaan mordan $\mathrm{CaCO}_{3}$ dan pencelupan menggunakan limbah yang tidak distabilkan merupakan perlakuan yang terbaik untuk kain sutera dengan nilai ratarata antara baik sampai baik sekali (4 dan 5). Bila dilihat dari jenis mordan atau pengikat warna, maka perlakuan dengan mordan kapur memberikan hasil pengujian ketahanan luntur warna terhadap sinar paling baik dan lebih baik dibandingkan dengan tawas dan tunjung dengan hasil baik (4), sedangkan untuk tawas dan tunjung dengan nilai cukup (3).

\section{DAFTAR PUSTAKA}

Badan Pusat Statistik. 2013. Sumatera Barat dalam angka. BPS Sumatera Barat.

Badan Pusat Statistik. 2013. Sumatera Utara dalam angka. BPS Sumatera Utara.

Badan Pusat Statistik. 2013. Riau dalam angka. BPS Riau.

Badan Standardisasi Nasional. 2010. SNI ISO 105-C 06: 2010. Uji ketahanan luntur warna terhadap pencucian $40^{\circ} \mathrm{C}$ (perubahan dan penodaan warna). BSN. Jakarta.

Badan Standardisasi Nasional. 2010. SNI ISO 105-B 01: 2010; Uji ketahanan luntur warna terhadap sinar terang hari. BSN. Jakarta.
Badan Standardisasi Nasional. 2010. SNI ISO 105-XII: 2010. Uji ketahanan luntur warna terhadap penekanan panas (nilai perubahan dan penodaan warna). BSN. Jakarta.

Badan Standardisasi Nasional. 1989. SNI 0283-1989. Cara penggunaan gray scale. BSN. Jakarta.

Badan Standardisasi Nasional. 1989. SNI 0284-1989. Cara penggunaan staining scale. BSN. Jakarta.

Chairat, M., Bremner, J.B.\& Chantrapromma, K. 2007. Dyeing of cotton and silk yarn with the extracted dye from the fruit hulls of mangosteen, Garcinia mangostana Linn. Fibers and Polymers, Vol. 8 No.6, pp. 613-619.

Dhalimi, A. 2006. Permasalahan gambir (Uncaria gambir L.) di Sumatera Barat dan alternatif pemecahannya. Perspektif, Vol. 5 No. 1: 46-59.

Etherington, R. 2002. A Dictionary of descriptive terminology: Vegetable Tannin.http://palimpsest.standart.edu. /don/dt.3686.html. Diakses tanggal 4 Januari 2014.

Failisnur dan Yeni, G. 2013. Stabilisasi limbah cair hasil pengolahan gambir dan aplikasinya sebagai pewarna pada kain sutera. Biopropal Industri, Volume 4 Nomor 1: 7-16.

Failisnur dan Sofyan. 2014. Sifat tahan luntur warna dan intensitas warna kain sutera dengan pewarna alam gambir (Uncaria gambir Roxb) pada kondisi pencelupan dan jenis fiksator yang berbeda. Jurnal Litbang Industri, Volume 4 Nomor 1: 1-8.

Hou, X., Wei, L., Zhang, X., Wu, H., Zhou, Q. \& Wang, S. 2008. Dyeing properties to wool fabrics of catechu dye purified by micro-filtration membrane. Research Journal of Textile and Apparel. Vol. 12 No. 1, pp.32-38. 
Kulkarni, S.S., Gokhale, A.V., Bodake, U.M., Pathade, G.R. 2011. Cotton dyeing with natural dye extracted from pomegranate (Punica granatum) peel. Universal Journal of Environmental Research and Technology. Volume1, Issue 2: 135-139.

Kwartiningsih, E., Setyawardhani, D.A., Wiyatno, A., Triyono, A. 2009. Zat pewarna alami tekstil dari kulit buah manggis. Ekuilibrium, Vol. 8 No. 1. Januari 42: 41-47.

Lukas, A. 2011. Pemanfaatan gambir sebagai pewarna kain kapas. Jurnal Dinamika Penelitian Industri, Vol. 22 No. 1: 19-28.

Mongkholrattanasit, R., Krystufek, J., Wiener, J. \& Vikova, M. 2011. Dyeing, fastness, and UV protection properties of silk and wool fabrics dyed with eucalyptus leaf extract by exhaustion process. Fibres and Textiles in Eastern Europe Journal, Vol. 19 No. 3: 94-99.

Patel, N. K. 2011. Natural dye based sindoor. Life Sciences Leaflets. 11. 355-361.

Rahmawati, N., Bakhtiar, A., dan Putra, D., P. 2012. Isolasi katekin dari gambir (Uncaria gambir (Hunter) Roxb) untuk sediaan farmasi dan kosmetik. Jurnal Penelitian Farmasi Indonesia, 1(1): 610.
Sachan, K. dan Kapoor, V. P. 2007. Optimization of extraction and dyeing conditions for traditional turmeric dye. IJTK, 6(2): 270-278.

Samanta, A. K. \& Agarwal, P. 2009. Application of natural dyes on textiles. Indian Journal of Fibre \& Textile Research. Vol. 34, No. 4, pp. 384-399, ISSN 0975-1025.

Siva, R. 2007. Status of natural dyes and dye-yielding plants in India. Current Science, 92(7).

Suheryanto, D. 2010. Optimalisasi celupan ekstrak daun mangga pada kain batik katun dengan iring kapur. Prosiding Seminar Nasional Rekayasa Kimia Dan Proses. Jurusan Teknik Kimia Fakultas Teknik Universitas Diponegoro Semarang.

Vankar, P.S., Shankar, R. and Wijayapala, S. 2009. Dyeing cotton, silk and wool yarn with extract of Garnicia mangostana Pericarp. JTATM, 6(1).

Zarkogianni, M., Mikropoulou, E., Varella, E., Tsatsaroni, E. 2010. Colour fastness of natural dyes: revival of traditional dyeing techniques. Coloration Technology; 127:18-27 